\title{
Avocado Pear as a Source of Inspiration for the Design of a Model Truck as a Desk Organiser
}

\author{
Isaac Kwabena Agyei ${ }^{1 *} \quad$ Peggy Ama Fening ${ }^{2} \quad$ Charles Adu-Boachie ${ }^{3} \quad$ Ofori Asare Amankwa ${ }^{4}$ \\ 1.Lecturer, Department of Industrial Art, Faculty of Art, College of Art and Built Environment, Kwame \\ Nkrumah University of Science and Technology, Kumasi, Ghana \\ 2.Senior Lecturer, Department of Industrial Art, Faculty of Art, College of Art and Built Environment, Kwame \\ Nkrumah University of Science and Technology, Kumasi, Ghana \\ 3.Lecturer, Department of Industrial Art, Faculty of Art, College of Art and Built Environment, Kwame \\ Nkrumah University of Science and Technology, Kumasi, Ghana \\ 4.MFA Student, Department of Industrial Art, Faculty of Art, College of Art and Built Environment, Kwame \\ Nkrumah University of Science and Technology, Kumasi, Ghana
}

\begin{abstract}
This publication seeks to explore and design a model truck with a concept idea development that will serve as a desk organizer. The automobile selected is a semi-truck that has a sleeper. The sleeper is what serves as a resting place for drivers during long journeys. This truck is best suited for the concept because of the sleeper to convey all necessary compartments to accommodate office supplies. Observation of most desk organizers found on the desk of some general offices are containers that have simple shapes like cylinders, boxes where items are placed. These organizers do not add any aesthetic appeal to the office since it's very simple and the items placed in them are not singled out thereby making accessing them inconvenient. There is also no distinct design that will make them stand out and also welcome the visitor. This research explores various design ideas of combining the truck concept into a desk organizer. The descriptive research and studio-based methods based on the qualitative research approach were employed. The researchers rather employed the use of an inanimate object being Avocado or Pear fruit as the design inspiration that guided all design experiments. The Latin word for Pear is 'Pirum', which means to 'bear fruit'. Every nation's income is partly dependent on the money generated from the movement of goods and services. Therefore, for a nation to bear fruit economically, the import and export of goods and services must be very effective. Trucks are very instrumental in conveying these goods and services across the country. The design is meant to serve as a wheel of academia where all necessary items needed at offices are well organized and conveyed for knowledge acquisition. To explore and produce further unique objects of product design that can serve a completely different purpose aside its original purpose or its aesthetic appearance and value was recommended. It was also recommended that there should be a form of collaboration with other departments to produce interesting results. There should be a collaboration between the Metal Product Design Section and the Engineering Section to produce works of art where the engineers introduce their technological concepts into the design ideas and concepts of the Metal Product Designer.
\end{abstract}

Keywords: model, truck, sentinel, desk organizer, avocado pear

DOI: $10.7176 / \mathrm{ADS} / 86-05$

Publication date:October $31^{\text {st }} 2020$

\section{INTRODUCTION}

An effort to research into organizing one's desk at offices have been made by a lot of researchers in various fields in the academia. Researchers have come up with models and modalities in this area to help put to shape the desk of lecturers and other people who own offices.

Computer scientists (Tomita et al. 2016) believe that because input interfaces such as keyboard and mouse are outside their working space, they must stop and move their working hand in order to operate them. In light of this example, the goal of their study was to devise a system by which the user can easily operate a computer or tablet while working on a desk. This to me was a means to help organize and manage properly an activity at the office.

Engineers (Ahmed et al. 2019) opine that different lighting techniques to illuminate an office are enclosed, implemented and compared to describe the different lighting solutions with maximum achievable efficiency and minimum losses. Those sensitive parameters that can affect the efficiency of lighting are addressed and their drawbacks are compared. This is a means to getting better illumination at offices for effective and efficient organization.

Spatially organizing objects in turn requires an algorithm to model a person's preferences as well as an object's attributes in order to infer spatial relationships suited to a particular task. In their paper, they investigated this problem further by focusing on the task of autonomous desk organization. They were particularly interested in exploring the role of an object's multimodal physical attributes and a person's organizational preferences in learning and inferring spatial relationships (Rowe, et al. 2019). 
The gap has been the effort of the metal artist in coming up with a unique design and production of a metal desk organizer to help organize especially items such as pens, pencils, call cards, erasers, pins and other related items which sometimes take people time to look for at their offices if not well organized.

An automobile or car is a wheeled vehicle that carries its motor and transports passengers. A car, which is also referred to as Automobile, is a self-propelled vehicle used primarily on public roads but adaptable to road surfaces. Cars are classified by their size, several doors, style, and intended use. A typical idea of an automobile is a car that has four wheels and can carry a maximum of six people, including the driver. However, the bigger vehicles which are designed to carry more passengers are called vans, minivans, or buses. Cars which are used to carry cargo are called pickups or trucks, which also depends on their size and design. The minivan is a van-style vehicle which is built on a passenger car frame and can usually carry a maximum of eight passengers. SUVs, known as Sport-utility vehicles, are tougher than passenger cars and can be driven in mud or snow (Bellis 2015).

Automobiles are very necessary for the day to day activities of people around the world. It makes the transportation of goods and services convenient and very effective. The Volkswagen group had a vehicle concept from the beetle insect. The external appearance of the Volkswagen model is a good representation of this beetle concept. Furthermore, the Lamborghini Company also design and produce vehicles and name them after Italian bulls. The models which were produced by this company were designed and named after Italian bulls such as Gallardo, Aventador, Diablo, etc. In the same vein, the desk is meant to convey all the necessary ingredients one will need in academia for success.

The automobile is primarily built around an engine. A system of components feeds the engine with fuel, the engine is however cooled with a radiator, lubricate its moving parts, and remove exhaust gases it creates. The engine produces mechanical power that is transmitted to the automobile's wheels through a drivetrain, which includes transmission, one or more driveshaft, differential gear, and axles. Suspension systems, which include springs and shock absorbers, cushion the ride and help protect the vehicle from being damaged by bumps, heavy loads, and other stresses.

All these mechanisms are designed and produced by product designers and engineers. Effort to research into organizing one's desk at offices have been made by a lot of researchers in various fields in academia. Researchers have come up with models and modalities in this area to help put to shape the desk of lecturers and other people who own offices.

\subsection{A brief history of cars}

As with many inventions, there is no defining point in history that states, "Today the car were invented."

Rather, it is an evolution of ideas and actions, beginning rather uneventfully with Leonardo da Vinci and Isaac Newton's theoretical plans for a motor vehicle that ultimately led to the invention of the first self-propelled vehicle. But neither of these brilliant inventors put his plan into action. The ultimate honour of the first motorized vehicle is attributed by most historians to Nicolas Joseph Cygnet, an engineer, and mechanic in the French Military (Dunton 2006)

Dutton continues to elaborate that other inventors around the world were quick to see the significance of Cugnot's inventions and picked up the baton in the race to build the car. Frenchman, Onesiphore Pecqueur, improved on Cugnot's early attempts and also invented the first differential gear. In 1789, American inventor Oliver Evans was granted the first US patent for a steam-powered land vehicle. Steam-powered vehicles were gradually improved by several other innovative characters around the world, but the vehicles remained rather cumbersome. Drawings of early vehicles depict large, ship-like structures on wheels with ungainly operating mechanisms. It's almost inconceivable to imagine these vehicles manoeuvring around the streets of 17 th Century Europe without causing damage and injury.

\subsection{Desk organizer}

They have the function of organizing office supplies with a variety of sizes, they also come in a variety of shapes and colours. Some designs are minimalistic while others are the complete opposite. Desk organizers also minimize the space consumed by the office supplies that are on the desk.

\subsection{Design}

This is what (Taura \& Nagai 2017) has to say about design. We discuss the issues of the "ability to design" and "thought behind the design" to formulate a definition of the term "design" that will be able to encompass these associative aspects. We classify design into three categories: drawing, problem-solving, and ideal pursuing. Moreover, based on these categories, we define design as "the composition of a desired figure toward the future."

The rational model design was very paramount in this design activity. This model was independently developed by (Simon 1969) and (Pahl and Beitz 1996). It suggests that:

1. Optimization of design to detect known constraints, as well as objective, is the reason for an attempt by 
the designer.

2. The process of the design is backed by a driven plan.

3. Through a discrete order of stages, the process of design is made meaningful.

Rationalist philosophy is outlined by (Brooks 2010) as the bases upon which this model is established and it brings about the Waterfall Model by (Royce 1970) and Systems Development Life Cycle by (Bourque \& Dupuis 2004). According to the rationalist philosophy, it is through an effort to search and to add to knowledge in a structured manner that a design can be formed. The process is also established on technical rationality.

\subsection{Sequence stages of design}

To better establish the Rational Model, an effort must be made to abide by the stages given below;

- Pre-production design

$\circ \quad$ There must be a briefing concerning the general aim of the design.

$\circ \quad$ The present goals of the design must be analyzed.

- Solution gotten from likely design topics must be investigated.

- Requirements to better obtain the design as specified must be followed (Cross 2008)

- There must be an effort to conceptualize and document the process of design.

- Design solutions must also be presented.

- Design during production

- Solution derived from design must be continued in an improved state.

- There must be a means through which design must be tested.

- $\quad$ Post-production design feedback for future designs

- The solution from the design must be introduced to the environment for implementation.

- Summary, suggestion as well as the criticism must be welcomed and done to conclude the process.

- The redesign is done to ensure perfection by which an effort is made to revisit the processes of earlier design to ensure accuracy through avoidance of earlier mistakes. The idea behind this is to ensure best practices (Ullman 2009).

\subsection{Criticism of the Rational Model}

The (Brooks 2010) model has gone through criticism on below grounds;

1. Those known to be good designers are not supposed to act based upon the outlined processes which were laid down by (Cross 2004).

2. There is the uncertainty of goals regarding processes of design and the likelihood of changes in possible limitations is high in that which was laid down by (Brooks, 2010).

\subsection{Design Philosophies and Concepts}

The modern design works and the need to encourage its implementation make it possible to have several philosophies that guide the design work coming from many schools of thought among practising designers (The Industrial Designers Society of America, 2013).

The focus in every design philosophy is to determine the goal of a design which is also to ensure that likely problems are resolved both small and big in a more holistic manner. The further issue relating to the goal of design will make room for a follow-up question and eventually lead to the provision of better solutions. This study makes use of the philosophy behind tracks for conveying items from one place to another where the desk is to serve as a channel of most of the things or items needed for academic pursuits.

\subsection{Philosophies for guiding design}

Design philosophies touch on things that are considered to be the laid down principles to ensure better approaches towards design by the designers as in this research by designing for a model truck which will serve as a desk organizer. It is guided by concerns of environment and other material culture in which manifesto from the First Things First is an example as it touched on things that are of concern to the environment including better communication medium and freedom, production, and marketing flexibility among many.

Design is a meta-discipline of all professions and not restricted to engineers but rather extends to other disciplines that seek to convert an existing way of art into a more modern way through design work (Simon 1996). It is obvious to know and appreciate the fact that the best in every profession is achieved through a process of design which makes it more outstanding as compared with other sciences. Schools of engineering, as well as schools of architecture, business, education, law, and medicine, are all centrally concerned with the process of design (Simon 1996). The philosophy guiding this project is the use of the Avocado to design the model truck to serve as a desk organizer for the office. Avocado has a lot of benefits to human health which helps to sustain the body and fight against a lot of diseases. Likewise, the use of it to design the model is to help 
members of the academia organize all the necessary tools and equipment they will need in one container to help them achieve and perform creditably in the fields of endeavours.

\subsection{Model making}

A model is a copy of a product or object, especially one which is made on a smaller size of the original object or product. A model is also described as the miniature representation of something or a type or design of a product. A model car is a miniature representation of an Automobile. Other miniature motor vehicles, such as trucks, buses, etc. are often the category of model cars this is because many miniature vehicles were originally aimed at children as toys or playthings. However, there is no precise difference between a toy car and a model car. Therefore, the word 'model' implies either a miniature representation for an assembly required product or some attempt at the accurate rendering of an actual vehicle at a smaller size (Gibson 1970, p. 9; Harvey 1974; Johnson 1998, p. 5).

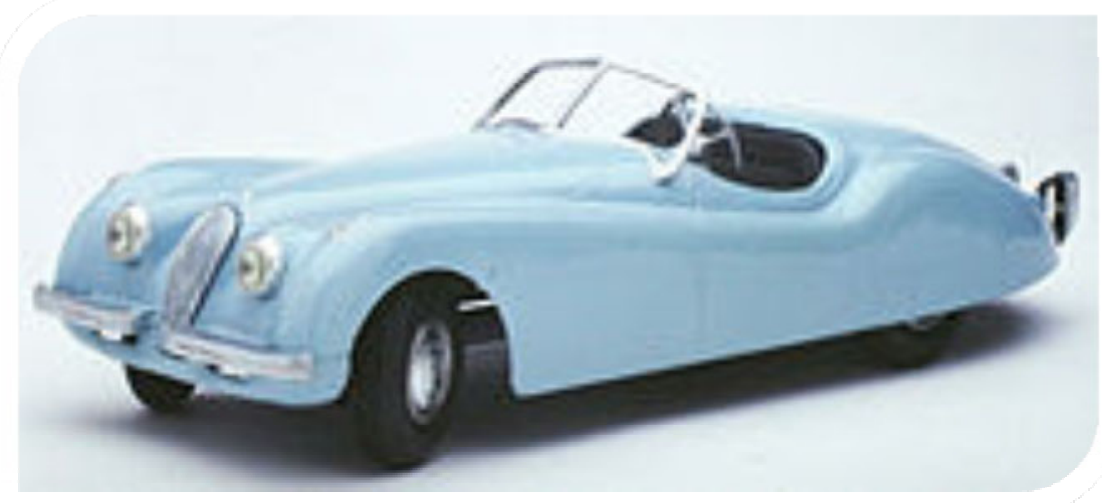

Fig. 1 Example of a model car

Source: www. Wikivisually.com, 2020

Fig.1 is a diecast 1:10 scale Doepke Toys Jaguar XK120 from 1955. One of two car models the company made, this model is 17.5 in $(440 \mathrm{~mm})$ long. (in The Children's Museum of Indianapolis). A miniature of something is the smaller-than-usual version of something original as seen in Fig 1

\section{TOOLS, MATERIALS AND METHODS}

Research is a logical and systematic search for new and useful information on a particular topic. It is an investigation of finding solutions to scientific and social problems through objective and systematic analysis. Research can lead to new contributions to existing knowledge. The results of scientific research very often force a change in the philosophical view of problems that extend far beyond the restricted domain of science itself. It is a search for knowledge, that is, a discovery of hidden truths. Here knowledge means information about matters. Only through research is it possible to make progress in a field. Research is indeed civilization and determines the economic, social, and political development of a nation (Rajasekar et al. 2013). The information might be collected from different sources like experience, human beings, books, journals, nature, etc.

The research methods that were used in carrying out this study are the Descriptive and Quasi-Experimental Research methods which were based on the Qualitative Research Approach. The descriptive research was however used to describe as well as document the design process before the desired results were achieved. This method further described the components of a semi-truck and how the design can be manipulated into a desk organizer which can accommodate a selected number of office supplies. The quasi-experimental research was used to test the designs to see how best they will suit the intended purpose. The designs were analysed and also experimented using cardboard and paper to know which of the designs will best suit the intended function.

Qualitative research is concerned with qualitative phenomenon involving quality (Rajasekar et. al 2013). Some of the characteristics of qualitative research/method are:

- It is non-numerical, descriptive, applies to reason, and uses words.

- it aims to get the meaning, feeling, and describe the situation.

- Qualitative data cannot be graphed.

- It is exploratory.

- It investigates the why and how of decision making.

Qualitative research is about collecting and analysing information in as many forms (Creswell 2014). However, the researchers employed the qualitative research approach based entirely on aesthetics and quality 
other than quantity which has to do with numbers and figures. Here the emphasis was placed on the quality of the model truck and its effectiveness to serve as a desk organizer for offices.

Descriptive research is conclusive, as opposed to exploratory. This means that descriptive research gathers quantifiable information that can be used for statistical inference on your target audience through data analysis. As a consequence, this type of research takes the form of closed-ended questions, which limits its ability to provide unique insights (Yin 2014). However, used properly it can help an organization better define and measure the significance of something about a group of respondents and the population they represent.

The descriptive research method was employed in the study of the review of related literature and also it was used with the aid of photographs to describe in detail how the selected design approaches were used in the designing of the car model. The research tools used were observation and documentation. Some of the resource centres the researchers visited during the study include the KNUST main library and the College of Art Library.

\subsection{Tools and materials}

Tools are objects designed to do a specific kind of work. It does not form part of the work. The tools which were used in executing the project were pliers (round nose plier, bent chain, flush cutter), metal ruler, shears, tweezers, rubber mallet, files (smooth and rough), jewellers' saw frame and piercing blades, dividers, compass, French curves, digital scale, pencil, punch and hand drill.

Equipment is items needed for a particular purpose. The equipment used for the project included guillotine and the drilling machine.

\subsection{Design Processes}

The design process was categorized into three stages. These were

- Initial Sketches of Trucks

- Idea Development

- Final Design

\subsection{Sleeper Truck as a model}

The type of truck that was chosen is the sleeper track (Fig. 2). The sleeper track is a semi-truck that has compartments attached to the cabin of the truck used for rest or a place for sleeping. With this knowledge, the designs were all connected to the components that make up a sleeper truck to understand the design and function of the truck. The figure below shows an image of a sleeper truck and its labelled components (Fig. 2)

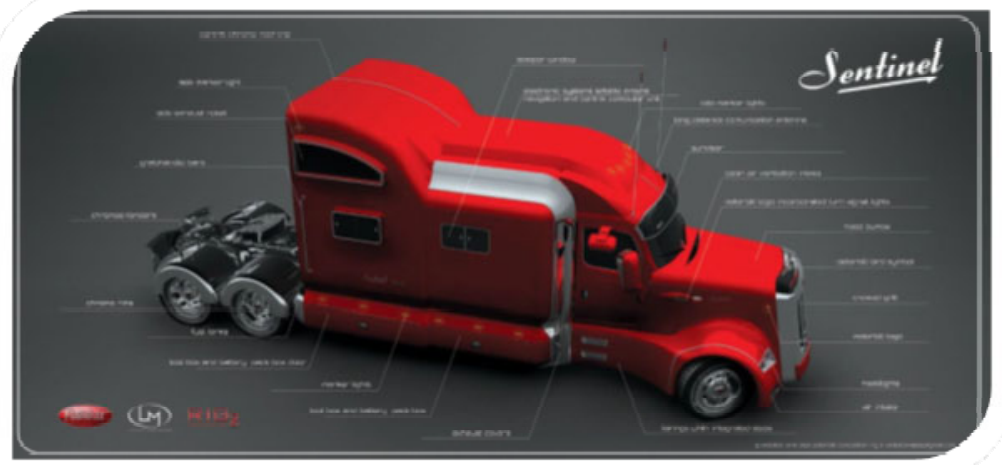

Fig. 2 Sentinel Semi-Truck and its components Source: www.tuvie.com;2020

\subsection{Initial Sketches of Trucks}

The figures below (figures 3-10) show a variety of pre-concept sketches aimed at understanding the concept of a sleeper truck, its components or compartments, and its design. These sketches (figures 3-10) gave a fair idea of the design of a sleeper truck and aided in the acquisition of various design ideas before the development of the concept. 


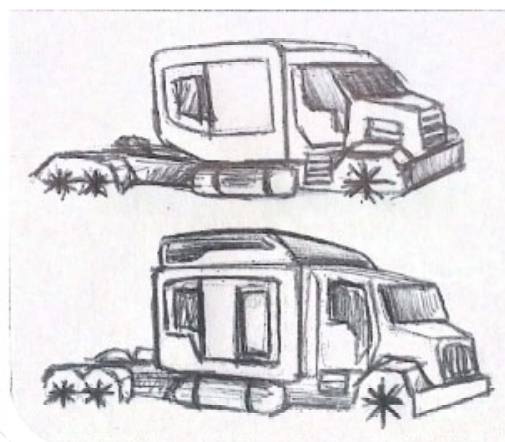

Fig. 3 Design 1

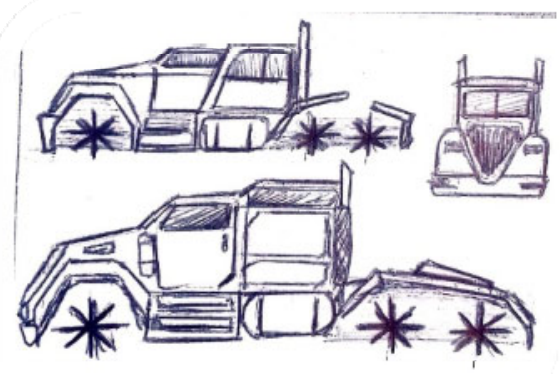

Fig. 5 Design 3

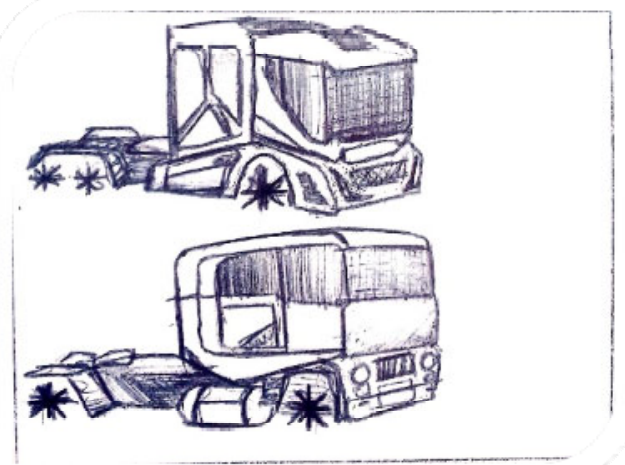

Fig. 7 Design 5

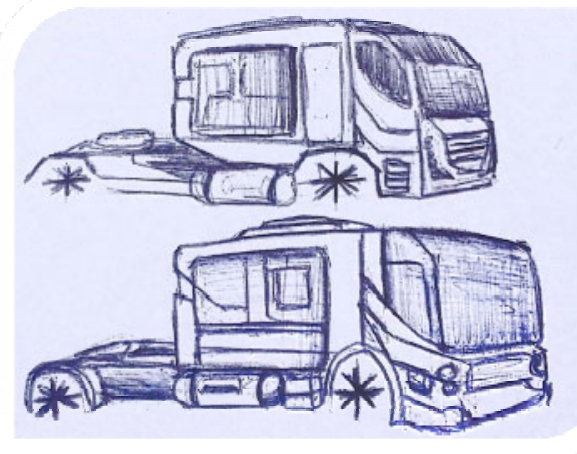

Fig. 4 Design 2

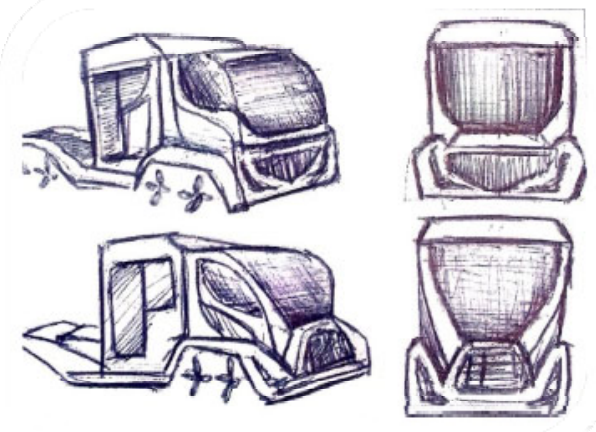

Fig. 6 Design 4

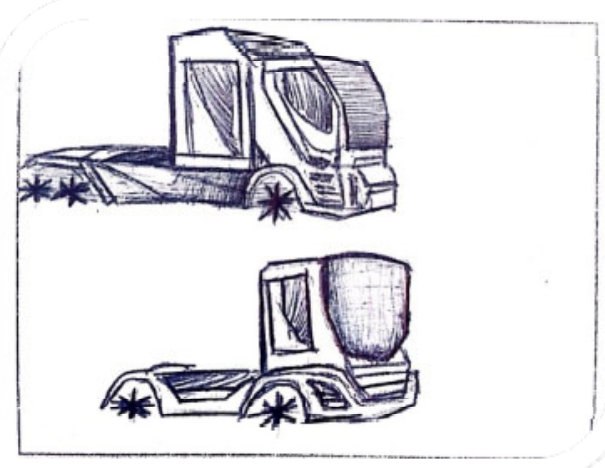

Fig. 8 Design 6 


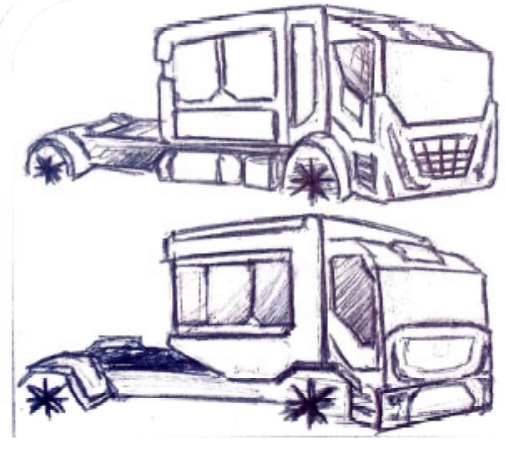

Fig. 9 Design 7

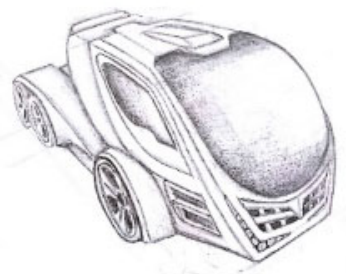

Fig. 10 Design 8

\subsection{Concept Deveiopment}

After acquiring adequate knowledge of the sleeper truck, a concept was conceived and developed into the final idea. The concept idea was developed around the pear fruit (fig.11). The automobile world of concept ideas has been inspired by animate things. Some of these are insects, animals, birds, etc. A typical example of this is the beetle model of the Volks Wagon group other examples include, Jaguar models, Lamborghini models, etc. However, the researchers developed their inspiration from an inanimate object being the pear fruit.

\subsection{The Pear Fruit}

The pear is any of several tree and shrub species of the genus Pyrus /pairs/, in the family Rosacea. It is also the name of the pomaceous fruit of these trees. Several species of pear are valued for their edible fruit, while others are cultivated as ornamental trees. The Latin word for Pear is 'Pirum', which means to 'bear fruit'. Every nation's income is partly dependent on the money generated from the import and export of goods and services. Therefore, for a nation to bear fruit economically, the import and export of goods and services must be very effective. Trucks are very instrumental in conveying these goods and services across countries.

The following sketches (Figures 11-22) show the implementation of the pear idea in the sleeper truck designs. Figure 23 shows a pencil rendering of the chosen design to give it a clear form. The designs were all connected to the pear concept. When viewed from the front, side, or rear, the viewer should see traces of the pear idea concept. To achieve this, the pear concept was highlighted in the following figures.

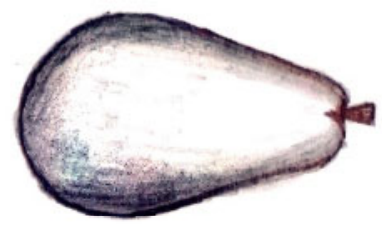

Fig. 11 Pear

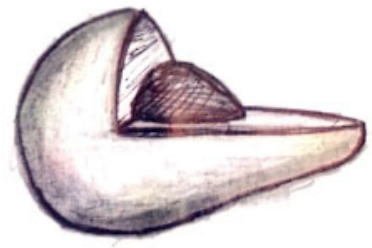

Fig. 12 Sketch 1 


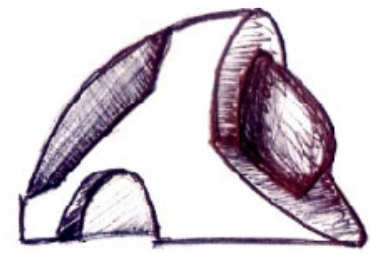

Fig.13 Sketch 2

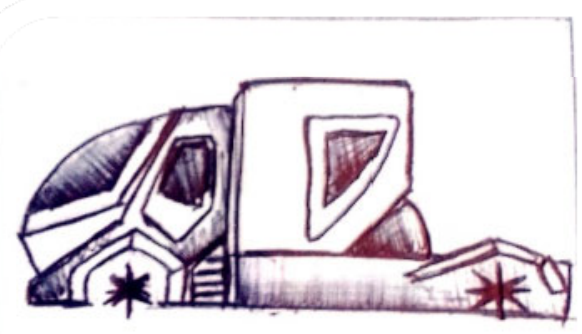

Fig. 15 Sketch 4

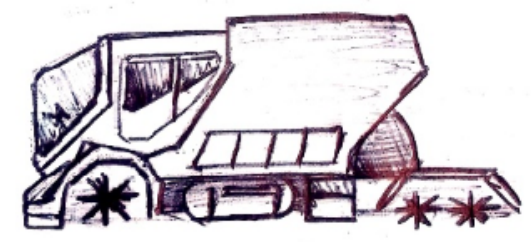

Fig. 17 Sketch 6

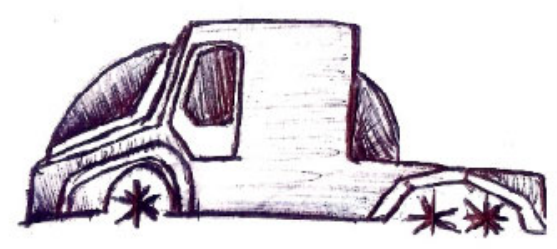

Fig. 14 Sketch 3

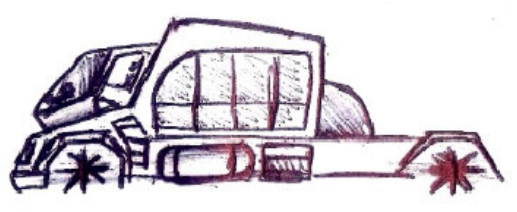

Fig. 16 Sketch 5

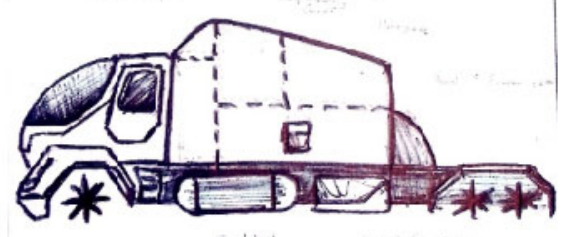

Fig. 18 Sketch 7 


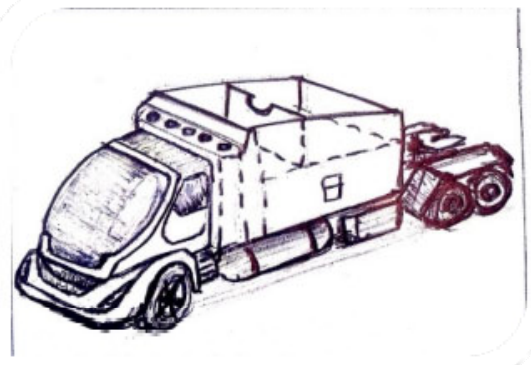

Fig. 19 Sketch 8

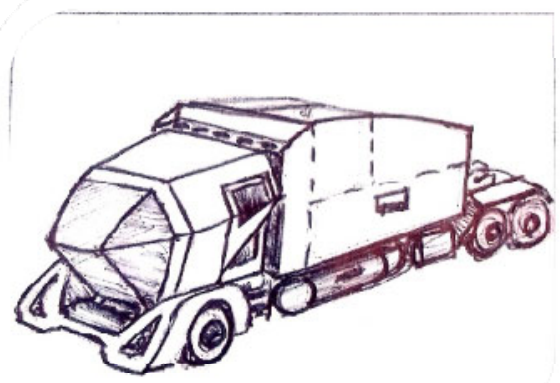

Fig. 21 Sketch 10

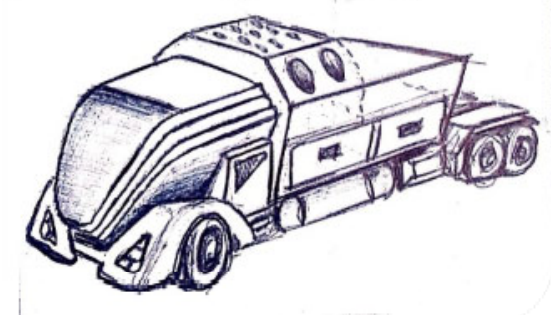

Fig. 23 Sketch 12
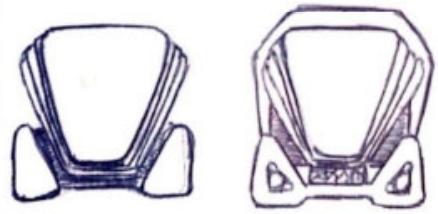

Fig. 20 Sketch 9

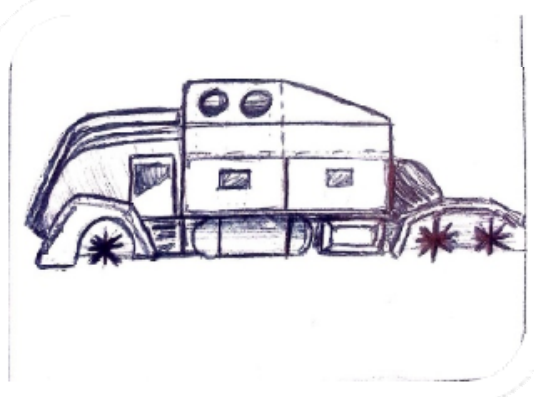

Fig. 22 Sketch 11

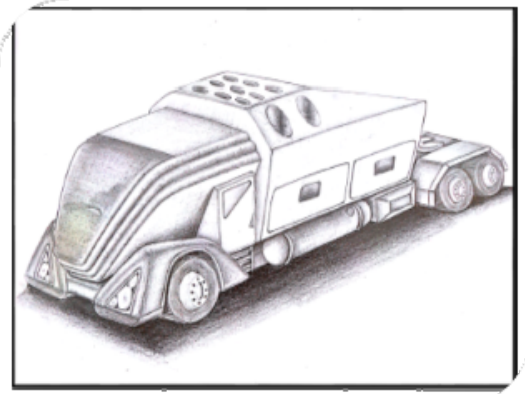

Fig.24 Pencil rendering

\subsection{Final Design}

After a critical analysis, the design in figure 22 perfectly fits the concept and conveys the pear idea when viewed from many areas. From the front end of the design, the pear idea was incorporated in the front wheel fender and the driver's cockpit. The side of the design also carries the pear idea. The cylinders represent the stem of the pear plant whereas the slanted nature of the back depicts the nature of the fruit when it is cut with a knife.

\subsection{Rendering of the Final Design}

To have a fair idea of how the truck model work will look like, the design was processed through the Rhinoceros 3D software (Figures 25-26). The figures (Figures 25-26) below are the results of the 3D modelling. 


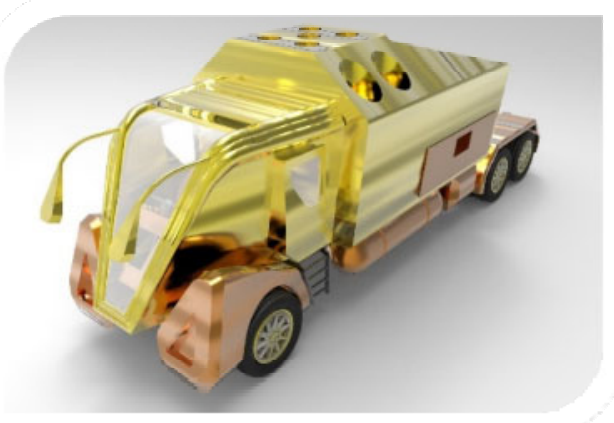

Fig. 25 3D Rendering 1

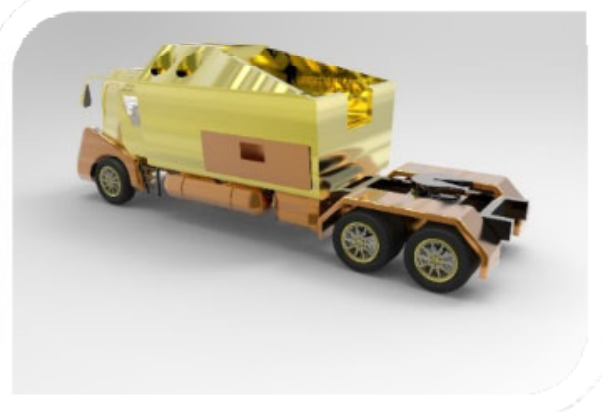

Fig. 26 3D Rendering 2

\subsection{Scale Drawing}

To commence the making process, a scale drawing (Figure 26) was done to give precise measurements and also to guide the researchers to produce accurate work.

The figure below (Figure 26) shows the scale drawing of the vehicle. This helped entirely in the making process since it contained measurements that were instrumental in producing precise work. The scale drawing was also displayed in segments to show contrast in the various components of the model. These segments were indicated with contrasting colours

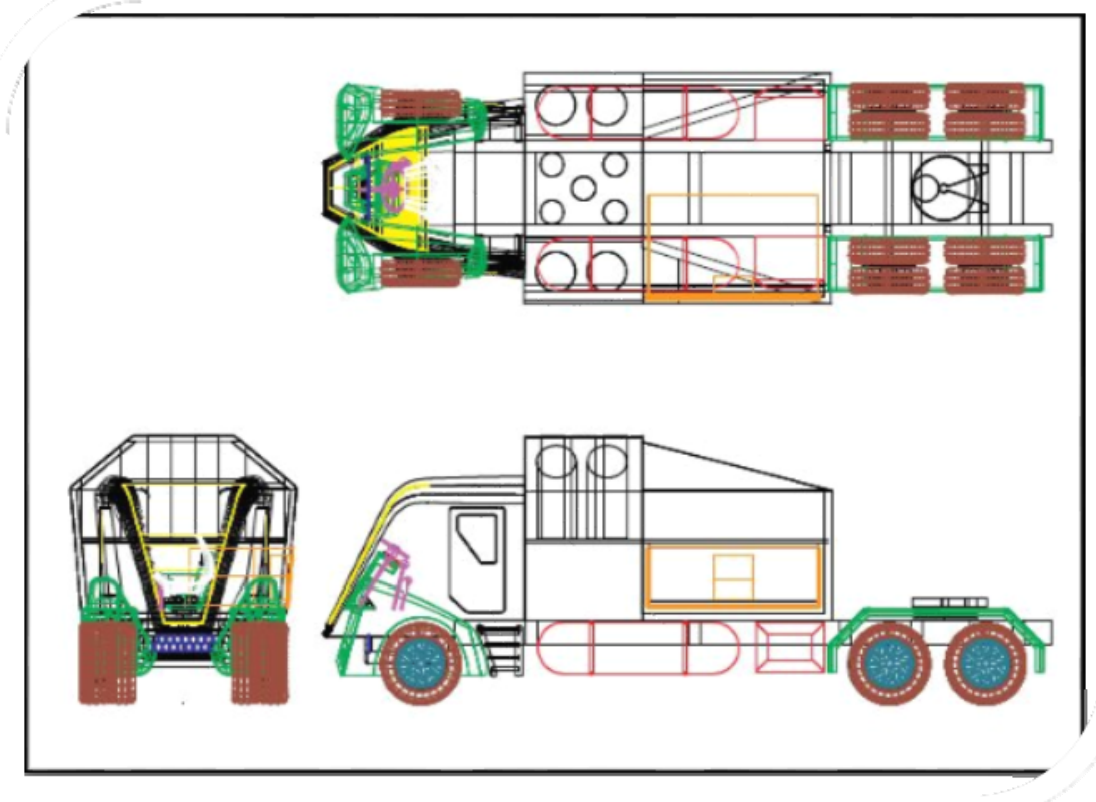

Fig. 27 Scale Drawing

\section{RESULTS AND DISCUSSION}

\subsection{Model}

A smaller model of the sleeper truck was constructed using cardboard and plastic. The scale drawing was further scaled down to produce the model. The entire body of the model was constructed with the strawboard. The tires are made up of plastic bottle lids. The smaller model helped effectively in the fabrication process. It gave a fair idea of how the fabrication will be executed since the forming process of the model will be conveyed into the fabrication process. 


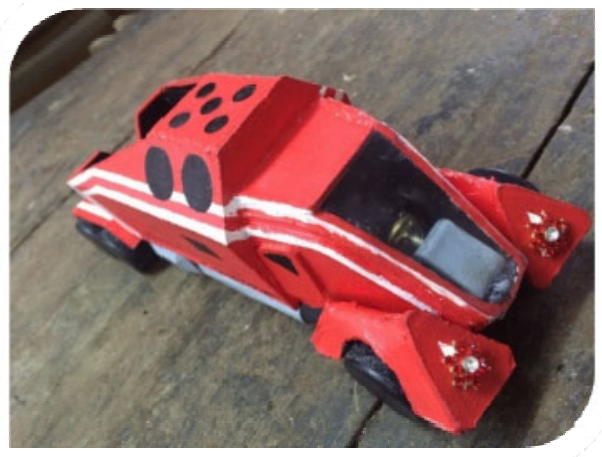

Fig. 28 Model 1

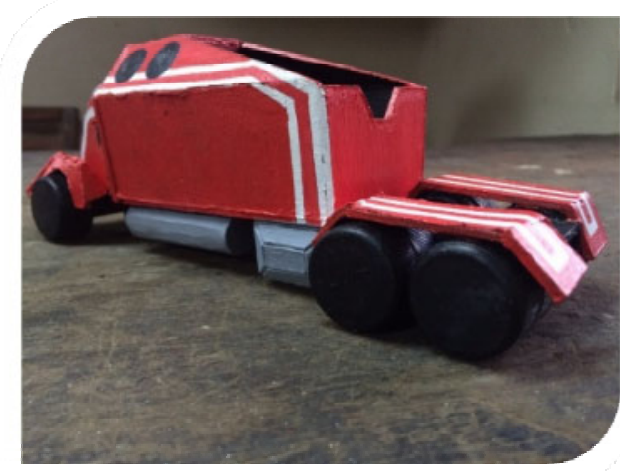

Fig. 29 Model 2

Figures 28 and 29 are the outcome or results of the project which are the miniature models of the truck meant to serve as a desk organizer for offices.

\subsection{Findings}

Different materials were used to produce the whole work. These materials are copper, brass, aluminium, iron, and plastic. Cardboard was used to form all the sheet components of the body of the model. A metal gauge of $1.5 \mathrm{~mm}$ was used to form the sleeper whereas the rest of the sheet components were a gauge of $1 \mathrm{~mm}$. The tools that were used to produce the model were a ruler, saw frame, files, stakes, and a rubber mallet. The ruler aided in obtaining the exact dimensions represented in the technical drawing. Due to the large cardboard, the saw frame that was used to cut the various shapes was small thereby making it a little difficult to cut certain angles. The bending was done on the stake. Grooves were made with a triangular file at the angle that will be bent. Some of the grooves were very deep making it very difficult to construct. The tires that were used were those of the small car toys. This could have been fabricated and could have made the model more interesting since the rims and the rubber tires could have been cast.

Tools and materials used for the design and the production of the model truck as a desk organizer were very efficient. The model had a lot of shapes and angles making it tedious to get the exactness of certain parts. Cardboard and plastics which were the main materials proved to be very efficient in the construction of the model truck. Adhesives for joining parts were very effective too. Utility knife which was also used for cutting all the parts to size and shape was effectively instrumental.

The model cars that are produced worldwide are either production required or for collecting. Some of the models are also produced as souvenirs and toys to promote the automobile company. The researchers' objective for carrying out this project was to design a model truck (automobile) that will serve a distinct function other than being a plaything.

Most of the desk organizers in the offices of some lecturers in K.N.U.S.T. and other nearby schools in the metropolis that the researchers visited were just simple geometric shaped objects with compartments of storage without any artistic feel and aesthetic appearance added to it. They were just container units joined together. Some of them were even just cylindrical containers where the users place many pencils, pens, and markers. This makes picking up specific objects whether pen or pencil less pleasant. However, the model truck organizer has an evenly spaced marker and pen slots which makes picking up any of this item very easy, and also there is a neat presentation of this item. The model also has an aesthetic appeal attached to it since it is not just a mere truck model but a model truck and at the same time a desk organizer.

\subsection{Driver's cockpit}

The front of the driver's cockpit is a little narrow due to the aerodynamics of the design. This makes the front of the model appealing to look at. There are two projections from the bottom of the head that covers part of the chassis where holes are drilled through both the head and the chassis to receive a screw to fasten the head unto the chassis. The doors of the head cannot be opened which makes that part of the work rigid. There are also no components inside which also makes the model less interesting to look at from the front view. Another discovery that would have made the model more interesting is if the head could bend to and fro on the chassis and also served as a storage device for small objects like complimentary cards.

\subsection{Sleeper}

The sleeper has a storage capacity of holding five pens, pencils, or small markers with $1 \mathrm{~cm}$ diameter or less. The 
big two slanted slots on both sides are marker slot which also has the capacity of accommodating markers of $2 \mathrm{~cm}$ diameter or less. These slots have been well spaced to make picking and replacing them easier and convenient instead of the others which are mostly cramped in one container with all types of pens and markers making it uncomfortable picking items. More so, the items that are to be placed in these slots are very limited therefore cannot hold more items. The drawer has a storage volume of $9.2 \mathrm{~cm} \times 11.5 \mathrm{~cm} \times 3.4 \mathrm{~cm}$ which can accommodate a small stapler, complementary cards, etc. The drawer however does not flash completely with the surface of the side of the sleeper. There is space at the drawer opening which could trap dirt inside the drawer because it does not completely cover the drawer opening.

\subsection{Chassis}

The chassis is a long aluminium frame that holds all the components. The aluminium was the appropriate metal for the chassis since it was the lightest metal available and it made the work feel light and also added an aesthetic feel to the work due to its contrasting colour. The chassis would have been more interesting if it had been mirror finished. Some of the screw threads became loose from time to time since they were being removed and fixed during the assembly period.

\subsection{Toolkit}

The toolkit is a base element that was placed adjacent to the fuel tank. It was so small it wouldn't be able to hold any important office supply item. It, however, serves as a decorative piece instead of being a storage component as the name connotes.

\subsection{Fuel tanks}

These fuel tanks are equipped with a flappy sheet protruding from the middle of the tanks which can be held with just two fingers to be moved left or right following the locking mechanism to either fix or remove them. One end of the fuel tank can be turned left or right to either open or close to feed the tank with more thumbnails or to take them out. The fuel tank has the capacity of containing a hand full of thumbnails each. The researches also discovered that the locking mechanism of the fuel tank is weak since when the model is raised, the fuel tank can fall out and the design can get distorted or disfigured. They are also too close to the floor and can get scratched if it is frequently moved on the desk. There should have been an inscription giving instructions on how to open and close the container.

\subsection{Rear fender}

The rear fender covers four tires. The tires were purchased after the fender had been fabricated. After purchasing the tires, the fender was too big, therefore it had to be reduced hence the middle line on each fender. The tires were also not properly fixed concerning balance and spacing. So when the model is pushed to and fro the tires rubbed on each other.

\subsection{Front fender}

The front fender carries traces of the pear concept concerning its shape. The middle portion also carries the front lighting fixture which consists of two LEDs each that can give the desk an amazing lighting effect. The front fender unit also hides all mechanisms and other spaces. The wheel slots, however, have some spaces which could trap dirt that will be difficult to clean.

\section{SUMMARY, CONCLUSION, AND RECOMMENDATION \\ 4.1 Summary}

As stated earlier in the statement of motivation, the project was aimed at producing a model sleeper truck with selected design and modeling techniques which will not only be a decorative piece but serve the function of a desk organizer. It also drew inspiration from an inanimate object being a pear and interesting shapes and designs were developed from it to arrive at the final design incorporating the model sleeper truck. The electrical component was also introduced in the model being the lighting system in the truck powered by a power bank to illuminate the desk of the user when the lights are out.

\subsection{Conclusion}

The following conclusion can be successfully drawn from the outcome of the project.

The successful execution of the project indicates that model cars can serve other functions such as desk organizers instead of being produced by automobile companies as production requirements or displayed at museums or collected by automobile collectors or sold as toys. Also, natural and inanimate objects can be combined harmoniously to form an art piece as a truck model which will serve as a desk organizer. Pear as the main source of inspiration has been very successful in the design of the model truck. 


\subsection{Recommendation}

This project has paved way for certain issues that can be addressed as a result of the recommendations below. To explore and produce further unique objects of product design which can serve a completely different purpose aside from its original purpose or its aesthetic appearance and value by combining different metalsmithing techniques such as the truck model which is a desk organizer.

The researchers also recommend that there should be a form of collaboration with other departments to produce useful results. For example, there should be a collaboration between the Metal Product Design Section and the Engineering Section to produce designs of art where the engineers introduce their technological concepts into the design ideas and concepts of the Metal Product Designer.

The section must also provide other tools and equipment to aid in the fabrication of complex shapes and designs. These tools and equipment could be a variety of pencils, compasses, dividers, rules, adhesives, cutters, design software, and cardboards. Some of the shapes in the design of the project could not be achieved due to the absence of some tools and equipment.

\section{References}

Ahmed, M. T. Riaz, A. Raza, A. Zaib, M. A. Akbar and M. B. Sarwar, (2019) "Modeling and Simulation of Office Desk Illumination Using ZEMAX," International Conference on Electrical, Communication, and Computer Engineering (ICECCE), Swat, Pakistan, 2019, pp. 1-6, DOI: 10.1109/ICECCE47252.2019.8940756.

Bellis, M. (2016). History of Electric Vehicles. Accessed at http://inventors.about.com/od/cstartinventions/a/History-Of-Electric-Vehicles.htm on 13/09/2020

Bourque, P. and Dupuis, R. (2004). Guide to the software engineering body of knowledge (SWEBOK). IEEE Computer Society Press

Brooks, F. P. (2010). The design of design: essays from a computer scientist. Addison-Wesley Professional

Creswell, J.W. (2014). Research design: Qualitative, quantitative and mixed methods approach (4th ed.). Thousand Oaks, CA: Sage.

Cross, N. (2004). Expertise in design: an overview, Design Studies, 25 (5), 427-441

Cross, N. (2008). Engineering Design Methods: Strategies for Product Design, John Wiley \& Sons, London.

Dutton, D. (2006). A Naturalist Definition of Art. Journal of Aesthetics and Art Criticism, 64, 367-377

Gibson, C. (1970). Commercial Vehicles. Troy Model Club Series. London: Thomas Nelson and Sons.

Harvey, B. (1974). Motoring in Miniature. The World of Automobiles: An Illustrated Encyclopedia of the Motor Car, Vol. 17, pp. 1995-1998. London: Orbis Publishing, distributed by Columbia House.

Johnson, D. (1998). Collector's Guide to Diecast Toys \& Scale Models, $2^{\text {nd }}$ Edition. Padukah, KY: Collector Books, a Division of Schroeder Publishing.

Pahl, G., and Beitz, W. (1996). Engineering Design: A Systematic Approach. London: Springer Verlag.

Rajasekar, S., Philominathan, P., and Chinnathambi. (2013). Research methodology. Retrieved September 13, 2020, from http://arxiv.org/abs/physics/0601009

Rowe, R., Singhal, S., Bhattacharjee, D. Yi, T. and Srinivasa, S. S. (2019). "Desk Organization: Effect of Multimodal Inputs on Spatial Relational Learning, 28th IEEE International Conference on Robot and Human Interactive Communication (RO-MAN), New Delhi, India, 2019, pp. 1-8, DOI: 10.1109/ROMAN46459.2019.8956243.

Royce, W.W. (1970). Managing the development of large software systems: Concepts and techniques.' In proceedings of Wescon.

Simon, A.H. (1969). The sciences of the artificial. MIT Press Cambridge MA. USA

Simon, H.A. (1996). The Sciences of the Artificial. 3rd ed. Aufl. Cambridge, MA: MIT Press

Taura, T. and Nagai, Y. (2017). Creativity in Innovation Design: the roles of intuition, synthesis, and hypothesis. International Journal of Design Creativity and Innovation, 5(3-4), 131-148

The Industrial Designers Society of America (2013). Design Thinking: New Innovative Thinking for New Problems. Accessed at https://www.interaction-design.org/literature/article/design-thinking-newinnovative-thinking-for-new-problems on 1/06/2020

Tomita H., Vasilache S., Tanaka J. (2016). Using the Office Desk as a Touch Interface. In: Yamamoto S. (eds) Human Interface and the Management of Information: Information, Design and Interaction. HMI 2016. Lecture Notes in Computer Science, vol 9734. Springer, Cham. https://doi.org/10.1007/978-3-319-403496_57

Ullman, D.G. (2009). The Mechanical Design Process, 4th edition. New York: McGraw Hill

Yin, R.K. (2014). Case Study Research Design and Methods (5th ed.). Los Angeles: Sage Publication 